\title{
O "Amor Brasileiro" de Vsiévolod Ivanov
}

\section{Vsevolod Ivanov's "Brazilian Love"}

Autor: Cássio de Oliveira

Edição: RUS Vol. 11. № 17

Data: Dezembro de 2020 


\section{O "Amor Brasileiro" de Vsiévolod Ivanov ${ }^{1}$}

Cássio de Oliveira*

Resumo: Em 1926, Vsiévolod Ivanov, um pioneiro escritor soviético canonizado nas páginas da legendária revista Krásnaia Nov, publicou um conto intitulado "Um amor brasileiro" na revista ilustrada 30 Dniêi. Não há indícios de que Ivanov tenha visitado o Brasil, sugerindo que a representação do país no conto é baseada em informação de segunda mão; por outro lado, em "Um amor brasileiro" Ivanov não só produz um estereótipo de uma cultura distante e exótica, mas também transpõe questionamentos da realidade soviética para aquele mundo, gerando uma espécie de tradução cultural das incertezas do projeto bolchevique para uma mítica Floresta Amazônica povoada, literalmente, por emigrantes russos.

\begin{abstract}
In 1926, Vsevolod Ivanov, a pioneering Soviet writer canonized on the pages of the legendary journal Krasnaia Nov, published a short story entitled "A Brazilian Love" in the illustrated magazine 30 Dnei. There is no evidence that Ivanov ever visited Brazil, suggesting that the representation of the country in the short story is founded on second-hand information; on the other hand, not only does Ivanov produce a stereotype of a distant and exotic culture in "A Brazilian Love," but he also transposes onto that world a lingering hesitation regarding the Soviet reality, generating a kind of cultural translation of the uncertainties of the Bolshevik project into a mythical Amazon Forest literally inhabited by Russian émigrés.
\end{abstract}

Palavras-chave: Vsiévolod Ivanov; Tradução cultural; Ornamentalismo Keywords: Vsevolod Ivanov; Cultural translation; Ornamentalism 
* Professor assistente de Russo no Departamento de Línguas e Literaturas Mundiais, Portland State University, Portland, Oregon, Estados Unidos. PhD em Línguas e Literaturas Eslavas pela Yale University. Especialista em literatura e cultura soviéticas do período entreguerras. https:/l works.bepress.com/cassio-deoliveira/; cassio@pdx.edu; https:// orcid.org/0000-0002-0250-0063

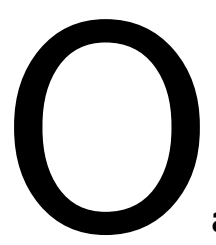

autor russo-soviético Vsiévolod Viatcheslávovitch Ivanov (1895-1963) foi um dos pioneiros do que se pode chamar de uma literatura legitimamente pós-Revolução. Natural da Sibéria (vila de Liebiájie, atualmente no norte do Cazaquistão), Ivanov se estabeleceu no firmamento literário soviético como autor de contos e novelas do front siberiano da Guerra Civil, predecessores temáticos do famoso Exército de cavalaria de Isaac Bábel. No que tange ao seu estilo e desenvolvimento de elementos formais, Ivanov se alinha aos "Irmãos Serapião", com os quais se associou no começo de sua carreira, como Mikhail Zóshchenko e Liev Luntz, com forte ênfase na trama e uso frequente de técnicas do skaz. Junto de Boris Pilniák, Ivanov foi uma das primeiras estrelas na rubrica de literatura da revista Krásnaia Nov (Terra virgem vermelha). A revista havia sido fundada em 1921 pelo poderoso Alexander Vorônski, que se tornou na prática um mecenas dos "companheiros de viagem" (popútchiki), autores admirados pelo seu talento com aspectos técnicos e formais da literatura, porém ainda não comprometidos politicamente com a causa bolchevique (mas tampouco hostis à causa, ao contrário de muitos intelectuais no exílio). Entre os Companheiros de viagem se incluía àquela época o próprio Ivanov, e Krásnaia Nov se tornou o principal veículo para a sua consagração na primeira metade dos anos $1920 .^{2}$

Este breve prefácio sobre o estágio inicial da carreira de Ivanov se faz importante para que se entenda tanto o prestígio de que o autor desfrutava, quanto a encruzilhada em que ele

\footnotetext{
1 Pelo generoso apoio à pesquisa para este artigo na forma de uma Bolsa de Estudos (Summer Stipend), o autor agradece ao National Endowment for the Humanities (NEH), uma agência do governo federal norte-americano. As opiniões, descobertas, conclusões, ou recomendações expressas neste artigo não refletem necessariamente aquelas do NEH.
}

2 Sobre Ivanov, v. Brougher, 2003, passim, e a introdução por Brougher em Ivanov, 1998, xiii-xxxvii. Sobre Krásnaia Nov, v. MAGUIRE, 1987, passim. 
se encontrava em meados da década de 1920. Àquela época, Ivanov já havia perdido um pouco do seu brilho, ofuscado por uma nova geração de autores que haviam caído nas graças de Vorônski, como Bábel e Leonid Leônov. Ao mesmo tempo, como explica Robert Maguire, naquela mesma época a obra de Ivanov passa por mudanças: ele evita os temas de cunho militar que haviam caracterizado suas obras anteriores; simplifica suas tramas e tenta desenvolver seus personagens de modo mais aprofundado, não só como vítimas das circunstâncias (como havia feito anteriormente), mas também como agentes de seu próprio destino. ${ }^{3}$ É nesse contexto que "Um amor brasileiro" ("Brazílskaia liubóv") um conto curto do autor, é publicado no número 2 de 1926 da revista ilustrada mensal 30 Dniêi (30 dias).

A revista 30 Dniêi é bastante diferente da Krásnaia Nov, esta se origina do espírito inovador dos primeiros anos depois da vitória bolchevique na Guerra Civil, enquanto aquela, fundada somente em 1925, é um produto bastante indicativo das políticas culturais do auge da Nova Economia Política (NEP). ${ }^{4}$ Fenômeno deveras inusitado no contexto soviético, a revista 30 Dniêi, segundo o seu editor Vasíli Reguínin, tinha sido inspirada por revistas ilustradas europeias, ${ }^{5}$ sendo um órgão mais acessível às massas, em especial à incipiente classe média urbana da NEP, 6 do que Krásnaia Nov, que afirmou desde o começo as suas credenciais de elite intelectual, um órgão da intelligentsia soviética. Embora 30 Dniêi seja lembrada atualmente principalmente por ter sido a revista em que $A s$ doze cadeiras e $O$ bezerro de ouro, os dois romances de Iliá Ilf e Ievguêni Petrov, apareceram pela primeira vez em episódios entre 1929 e 1931, a revista é digna de nota também por sua combinação de artigos de interesse geral com obras literárias, e por sua atenção especial para notícias ou temas gerais es-

3 MAGUIRE, 1987, 146.

40 panorama dos temas da revista 30 Dniêi nos parágrafos seguintes resulta da minha pesquisa dos números da revista publicados entre 1925 e 1939 (a publicação da revista cessou com a invasão nazista em 1941).

5 REGUÍNIN, s.d., RGALI, f. 1433, op. 3, ed. kh. 90, I. 12.

6 SITKOV, 1929, 39. V. também de Oliveira, 2018, s.p. 
trangeiros. Alguns dos artigos versam sobre tópicos um tanto curiosos, sobretudo em um órgão de imprensa soviético supostamente atrelado ao racionalismo científico bolchevique: eugenia, crematórios, hipnotismo, produção de chocolate, ou moda e penteados populares na Europa. No entanto, esses temas se tornarão mais raros conforme a Nova Economia Política se aproxima do fim e Stálin consolida seu poder. Mais importantes são os relatos de viagens, que demonstram grande interesse, beirando a obsessão, com partes do mundo consideradas exóticas: o Oriente Médio, Afeganistão, Tibete, Índia, Turquia, Congo Belga, etc. Em relação à literatura, 30 Dniêi publicou, desde o início, contos de autores promissores ou já consagrados: além de Ilf e Petrov, obras de Bábel (incluindo partes do Exército de cavalaria e o famoso conto "Guy de Maupassant"), Valentin Katáiev, Iuri Oliécha, Iliá Erenburg, Vera Inber, Mikhail Príchvin, além de muitos outros, incluindo autores estrangeiros simpáticos à causa comunista e publicados em tradução, como Henri Barbusse, Langston Hughes e Jaroslav Hašek. A literatura paulatinamente assume posição dominante na revista. Em meados da década de 1930, em seguida à fundação da União de Escritores da União Soviética que havia dado fim à guerra internecina entre diferentes facções artísticas, 30 Dniêi se torna um órgão exclusivamente literário, dedicado principalmente a gêneros prosaicos curtos (contos, poemas em prosa, noveletas) e à poesia.

Semelhantes aos relatos de viagem, muitos dos contos publicados na revista demonstram claro interesse em terras estrangeiras ou exóticas, desde a Ásia Central até a Europa e mais além. Nesse contexto, "Um amor brasileiro", como narrativa sobre as aventuras brasileiras de um cidadão soviético proveniente do vale do Rio Volga, é manifestação característica dessa combinação de literatura com viagem. O próprio Ivanov, vale lembrar, havia se consagrado com uma série de textos que mostravam o sul da Sibéria, sua região natal, por um prisma exótico, e alguns anos mais tarde seus contos sobre as repúblicas soviéticas da Ásia Central também viriam a aparecer nas páginas de 30 Dniêi. É notável que, a despeito do alcance geográfico dos relatos de viagem, nenhum dos 
correspondentes da revista havia publicado despachos sobre a América Latina, nem viriam a publicá-los em anos seguintes, pelo que me foi possível constatar. De certa forma, o conto de Ivanov ocupa precisamente um nicho deixado em aberto por aqueles relatos, porém sem insinuar, ao contrário daqueles textos, que a narrativa seja baseada em eventos reais.

Tal ausência de afirmação do realismo da narrativa é importante, mas por razões diferentes do que se esperaria: afinal de contas, a temática de 30 Dniêi, e o fato de muitos autores de literatura também contribuírem com relatos de viagem ou outros tipos de despachos de terras distantes, torna a distinção entre literatura e não-literatura um tanto arbitrária. Ademais, é também sintomático da negociação entre ficção e realidade que domina as páginas de 30 Dniêi que o texto de Ivanov possa ser descrito, em suma, como uma narrativa da viagem do narrador para o Brasil e de volta para a União Soviética (via Chicago); ora, narrativas de viagem em si são associadas à origem do gênero do romance moderno europeu. ${ }^{7}$ Os dois tipos de narrativas compartilham convenções formais, incluindo, frequentemente, a sugestão da verossimilhança da trama e a perspectiva de um narrador-protagonista. É precisamente esse caráter ambivalente do conto, como um híbrido de obra de ficção e narrativa de viagem à moda do skaz, que será o tema da análise que se segue.

Antes de tudo, um breve resumo da trama: Ivan Abrámovitch ou Vániuchka, natural da região de Sarátov, às margens do Volga, e pescador de belugas no Mar Cáspio, se muda para Moscou, onde estuda artes plásticas e se torna um pintor. Ele é convidado para exibir seus quadros em Chicago, incluindo um retrato do líder bolchevique Karl Radek, mas sugere em contrapartida uma visita ao Brasil antes de ir a Chicago. Chegando ao Brasil, ele se dirige à Amazônia, onde, a bordo de um barco a vapor, conhece dois padres que o tratam com hostilidade ao descobrirem que ele veio da União Soviética, famosa por seu ateísmo. Seu intérprete na conversa com os padres é um cozinheiro do barco, um russo chamado Smirnóv. Ivan de-

7 V. HULME e YOUNGS, 2002, passim. 
cide desembarcar em um vilarejo às margens do Rio Amazonas chamado "Rio Grande de Paulo", onde ele faz amizade com outro (!) emigrante russo, Piotr Bogdânovitch Veliamínov, um ex-governardor-geral da província de Samara que se tornou latifundiário, proprietário de uma grande fazenda de algodão na floresta. Veliamínov é ávido leitor da imprensa emigrante russa e por isso acredita em vários estereótipos sobre a União Soviética. O filho do emigrante-fazendeiro é um idiota. Ivan também conhece Máchenka, sua filha, os dois se apaixonam e, com a bênção do pai, ficam noivos. Porém Ivan se cansa da visão negativa da União Soviética que ele continua a ouvir de seu futuro sogro, e dúvidas sobre o rumo que sua vida está levando começam a surgir conforme os planos do casamento progridem. Ele propõe a Máchenka que eles retornem para a Rússia, mas ela, tendo deixado o país ainda criança, não quer rever sua terra natal. Vániuchka resolve abandonar a fazenda de Veliamínov, dá suas tintas de presente para os índios locais, e retorna sozinho, primeiro para Chicago, e de lá para Moscou. Ele manda um telegrama para Máchenka convidando-a a visitá-lo, mas não recebe resposta. $O$ conto se encerra em um tom nostálgico, com Vániuchka concluindo que nunca tornará a rever sua amada.

Ainda que "Um amor brasileiro" não contenha, em si, nenhum ato de tradução (e nem tenha sido traduzido para outras línguas, aparentemente), o conto se insere tanto no contexto da teoria de consagração literária de Pascale Casanova, baseada em parte na prática da tradução, quanto no contexto da crítica, desenvolvida pelo antropólogo britânico Talal Asad, do conceito de tradução cultural. Ao longo de sua obra, e especialmente no ensaio "Consecration and Accumulation of Literary Capital", Casanova ressalta a importância da tradução literária como veículo de aceitação e canonização de autores da periferia cultural nos grandes centros literários (no contexto de seus estudos, o principal centro seria Paris). Casanova divide as linguagens literárias entre dominantes e dominadas: os autores que escrevem suas obras nestas têm interesse em serem traduzidos para línguas dominantes; para um determinado centro cultural, a produção de traduções, seja de línguas 
dominadas ou dominantes, serve como afirmação do status dominante da língua desse centro. Casanova não se detém em casos excepcionais, por exemplo no histórico de traduções exclusivamente entre línguas dominadas, que tendem a ser mais raras. Ela prefere se aprofundar na análise de exemplos mais comuns e familiares de autores pós-coloniais para os quais a tradução para o inglês ou francês é um grande marco de seu sucesso artístico. No entanto, a importância de sua análise para este estudo consiste precisamente no argumento de que a diferença entre línguas dominantes e dominadas é determinada, em grande parte, pela relação entre as duas línguas que produzem o original e sua tradução. ${ }^{8}$

No caso de "Um amor brasileiro", dois fatores são importantes: em primeiro lugar, a constatação de que, a despeito da popularidade dos autores realistas russos desde as últimas décadas do século XIX, em meados da década de 20 , a literatura russo-soviética ainda não havia se consagrado (para usar o termo utilizado por Casanova) no sistema literário mundial. Embora seja possível afirmar que o russo, por causa das contribuições de Tolstói, Dostoiévski e outros, já estava a caminho de se tornar uma língua dominante, no imaginário soviético ele ainda se assemelhava a uma língua dominada, como demonstram os exemplos das traduções para o russo de autores canônicos e populares franceses, britânicos, e norte-americanos na União Soviética durante aquela década - e, em contrapartida, a ausência de traduções de jovens autores soviéticos até o final da década. Se por um lado, então, um autor como Ivanov seria, no auge da NEP, um representante de uma tradição literária dominada (no sentido em que a sua orientação ainda se dá em relação a modelos culturais importados), por outro lado - e este é o segundo fator importante - a representação do Brasil nesta história representa em si uma espécie de afirmação do russo como língua e perspectiva dominantes. Isso se dá por meio de um curioso mecanismo de tradução cultural, através do qual o Brasil se torna uma terra exótica radicalmente diferente da Rússia natal do narrador-protago-

8 V. CASANOVA, 2010, passim. 
nista, e simultaneamente uma versão sublimada, mítica, imaginária, porém também "domesticada" (para usar o termo de Lawrence Venuti), ${ }^{9}$ dessa mesma Rússia.

O processo pelo qual Ivanov incorpora a ideia do Brasil em sua narrativa se assemelha ao da tradução cultural. Asad critica o que ele percebe como a tendência, na tradição antropológica de Ernest Gellner, do efeito de estranhamento radical, no ato de tradução, da cultura "primitiva" observada pelo etnógrafo. Para Asad, Gellner comete uma forma de violência ideológica contra as culturas que ele observa ao traduzi-las sem tentar adaptar seu entendimento dessas culturas aos seus próprios contextos originais. Em outras palavras, Gellner, para Asad, produz uma espécie de tradução literal da cultura e, por isso, muitas vezes absurda sob o ponto de vista da cultura receptora. A solução seria o reconhecimento, pela língua e cultura receptoras, da necessidade de acomodar significados que possuem sua própria lógica interna. ${ }^{10}$ Ora, "Um amor brasileiro" não é uma etnografia, mas de certa forma seu narrador entra em contato com o que ele entende como a cultura brasileira por intermédio de um ponto de vista semelhante ao do etnógrafo. Ao desembarcar no país, numa região à qual ele simplesmente se refere como o sul mas que provavelmente é o Sudeste (provavelmente o Rio de Janeiro), Vániuchka descreve principalmente a umidade, o calor e os habitantes do país: "Os negros ainda vivem a andar para todos os lados, e os índios, esses mesmos enrolados em lençóis, então esses aí, para dizer a verdade, são piores do que os calmucos", ${ }^{11}$ um povo nômade de origem mongol. Depois dessas comparações não muito lisonjeiras, Vániuchka critica o tabaco fumado pelos índigenas, comparando-o negativamente ao chá verde dos calmucos, "uma delícia prazerosa" ("priiátnoie udovólstviie").12 O narrador, é claro, é diferente do próprio Ivanov, e o estilo da narrativa sugere que a história é uma forma de skaz, na qual o

9 V. VENUTI, 2018, passim.

10 V. ASAD, 2010, passim.

11 IVANOV, 1926, 22. Todas as traduções são do autor deste artigo.

12 IVANOV, 1926, 22. 
autor se relaciona ironicamente com o estilo do narrador. Ao mesmo tempo, o processo de tradução cultural se faz presente no sentido em que tanto Ivanov quanto seu personagem fazem uso da diferença cultural como um instrumento de humor, ressaltando o caráter estranho ou absurdo da população nativa.

Há indícios, no entanto, de que essa tradução cultural se transforma, quase que imperceptivelmente, numa manifestação de "domesticação" do mundo estrangeiro, aqui transformado em uma variação da Rússia. O que torna esse conto um exemplo intrigante da domesticação do estrangeiro é o fato de que o Brasil se assemelha, não necessariamente, a uma versão da Rússia, mas sim a uma versão do exótico mais próximo da experiência direta russa. $O$ primeiro indício desse processo é a comparação dos indígenas com os calmuques, referência a uma etnia periférica dentro do Império Russo e, depois, da União Soviética. Em outras palavras, Vániuchka não compara os indígenas, digamos, aos mujiques russos, mas sim a uma minoria étnica, enfatizando o exoticismo comum aos dois grupos. A bordo do barco a vapor no Rio Amazonas, Vániuchka compara os "portugueses"13 aos georgianos, sugerindo que todos os membros tanto de um grupo quanto do outro se vestem da mesma maneira. E quem seriam esses "portugueses"? Supõe-se que eles sejam brasileiros brancos, e aqui Ivanov também parece se guiar por uma perspectiva russo-soviética, na qual (a despeito de certos níveis de miscigenação) etnias tradicionalmente se distinguem umas das outras sem muita mestiçagem. ${ }^{14}$ Para ele, se georgianos, calmuques, eslavos, etc. tradicionalmente não se misturavam, o mesmo deve ocorrer necessariamente no Brasil.

Além de etnias, o conto também produz exemplos contundentes desse processo simultâneo de orientalismo e domesticação do Brasil no plano de estereótipos culturais. Um exemplo simples é o fato de que o emigrante Veliamínov é dono de fazendas de algodão em plena Floresta Amazônica. Deixando

13 IVANOV, 1926, 22.

14 Sobre o tratamento de minorias étnicas no Império Russo e na União Soviética respectivamente, v. KAPPELER, 2013, passim, e MARTIN, 2001, passim. 
de lado a questão puramente agronômica da possibilidade de se plantar algodão naquela região, o Brasil é mais famoso (e o era mais ainda nos anos 1920) pela produção de café. Ora, por que algodão então? Porque ele era o principal produto agrícola de uma região periférica da própria União Soviética, neste caso das repúblicas da Ásia Central como Uzbequistão e Tadjiquistão. Em um número de 1930 dedicado ao Primeiro Plano Quinquenal soviético, por exemplo, as repúblicas centro-asiáticas são descritas, coletivamente, como "a base fundamental produtora de algodão da União". ${ }^{15} \mathrm{O}$ estereótipo do Brasil, para Ivanov, consiste na reprodução de estereótipos de regiões periféricas da própria União Soviética.

Outros dois exemplos dizem respeito a personagens da trama. O primeiro são os padres, que (lembramos, por intermédio de um intérprete russo) questionam Vániuchka sobre as perseguições religiosas na União Soviética. Em seu interesse no destino do Patriarca Tíkhon (primeiro Patriarca Ortodoxo na era soviética, morto em 1925), os padres católicos servem de sátira a figuras religiosas (cristãs ortodoxas) dentro da própria União Soviética, por exemplo durante as campanhas antirreligiosas que periodicamente ocorriam e que eram dirigidas, na sua maioria, à Igreja Ortodoxa. O segundo exemplo, e possivelmente o mais contundente, é o de Máchenka. Se, por um lado, seu pai torcia para a queda do regime bolchevique para poder retornar à Rússia, por outro lado Máchenka se sente alienada do país natal, não por causa do regime político, mas simplesmente por causa do clima: "O que tem de bom lá - ela me responde: - só gelo, gelo todo azul. Eu não gostava do inverno, e ainda era garotinha, mal tinha aprendido a falar, quando me mandei para a Itália, para o sol. Eu só chorava no inverno... E o clima quente também é ótimo para os seus pulmões, Vánia". ${ }^{16}$

O que provoca a separação entre Vániuchka e Máchenka não é o fato de ela não gostar do inverno, mas sim o paralelo que isso suscita entre a situação de Vániuchka e a de seu pai, que havia abandonado a família para fugir com uma cigana.

15 Anônimo, 1930, 31.

16 IVANOV, 1926, 30. 


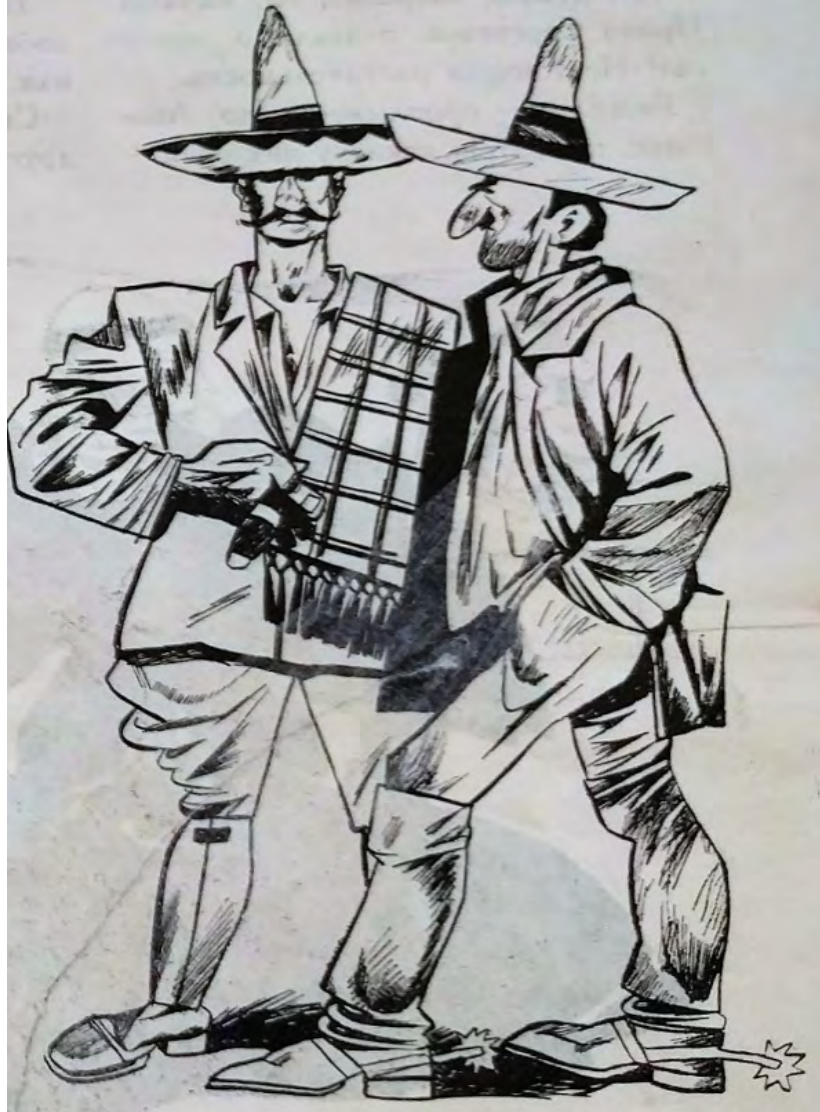

Португальџы ничем от наших грузин не отличаются
Desse modo, a temática da selva brasileira se espelha nos estereótipos literários russos, nos quais ciganos são amantes de aventuras e desfrutam de uma liberdade espontânea que está fora do alcance dos eslavos atormentados por questões existenciais. $O$ exemplo clássico é o poema narrativo "Os ciganos" ("Tzigáni", 1824), de Alexander Púchkin. Nele, o russo Aleko se apaixona pela cigana Zemfira e vive no povoado cigano junto com ela. Zemfira, no entanto, é incapaz de se manter fiel a Aleko, que, enlouquecido, a assassina junto com seu amante. Púchkin sugere que a infidelidade de Zemfira é característica essencial do seu povo, o qual, em seu amor à liberdade, se assemelha aos "bons selvagens" de Jean-Jacques Rousseau. $O$ "civilizado" russo Aleko encontra a perdição porque decide se juntar a um povo selvagem, cujo modo de vida é incompatível com sua própria existência. Em "Um amor brasileiro", Vániucha alude a um destino semelhante ao de seu pai (e de Aleko) se ele se casar com Máchenka: "Dá no mesmo, - assim como meu pai desapareceu com os ciganos e ladrões de cavalos, eu também vou desaparecer, seguindo o meu coração - em meio ao algodão, além do oceano". ${ }^{17}$

O resultado é que, ao contrário do que se poderia esperar de uma narrativa situada numa terra exótica sob o ponto de vista tanto do autor quanto de seus leitores, "Um amor brasileiro" acaba sendo um estranho híbrido, uma forma de orientalização de (esteró)tipos culturais que, dentro do próprio contexto russo-soviético, já eram exóticos o suficiente. O Brasil que aparece no conto e nas páginas da revista 30 Dniêi não é realmente o Brasil, mas sim uma terra fictícia que serve de espelho e projeção do Outro russo-soviético: georgianos, calmuques, ciganos, emigrantes Brancos e plantações de algodão.

17 IVANOV, 1926, 28-29. 


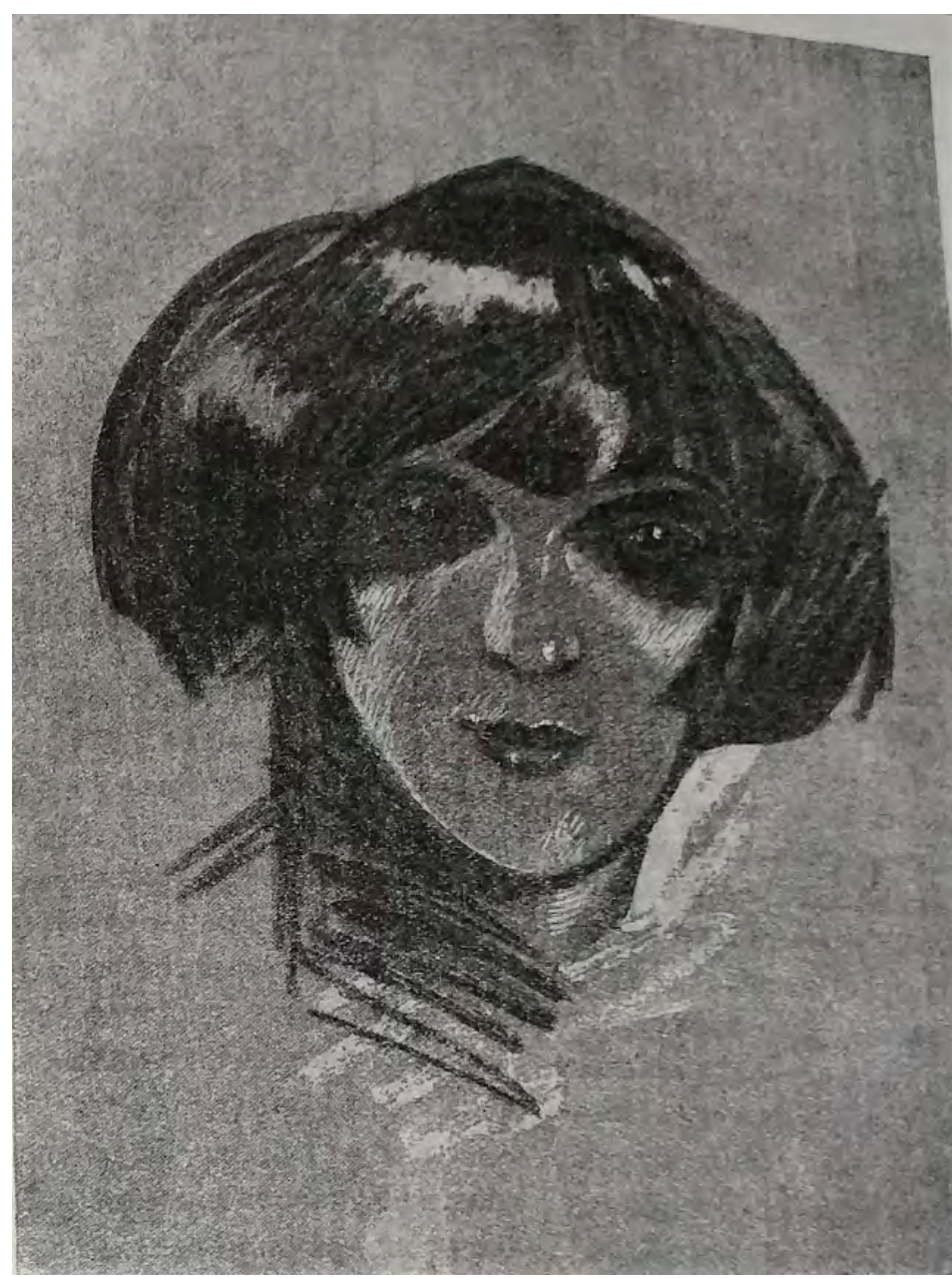

Fig. 2: 0 retrato de Máchenka, de autoria de lúli Ganf, para o conto "Um amor brasileiro" em 30 dniêi, v. 2, n. 2, Moscou, fev. 1926, p. 29. Fotografia do autor.
Prova dessa confusão ou desdém por um "realismo" mais convencional são as ilustrações que acompanham o conto, de autoria do artista Iúli Ganf: nelas, os "portugueses" carregam sombreros que os tornam parecidos com estereótipos visuais de mexicanos (ver figura 1).

Em outras ilustrações, os indígenas da Amazônia brasileira se assemelham mais a povos andinos ou Astecas nas suas vestimentas e fisionomias. Finalmente, no retrato da russa Máchenka (ver ilustração 2 abaixo), Ganf realça sua pele morena e seus cabelos negros e lisos. O retrato também é caracterizado por um nível de abstração, mostrando somente seu pescoço e cabeça em frente a um fundo neutro, de modo que qualquer contexto cultural é eliminado, sejam roupas ou um fundo realista. Pela perspectiva do artista, e consequentemente dos leitores do conto na revista (porque estes também encontrariam essas ilustrações ao ler o conto), os personagens se tornam figuras exóticas, sejam originários da periferia soviética ou de mais além. O Brasil não é realmente o Brasil, mas sim uma espécie de alegoria do que é diferente ou estrangeiro sob a perspectiva russa.

Em seu estudo da revista Krásnaia Nov, Maguire aborda o que, para ele, é uma interpretação errônea de Ivanov que perdura desde os escritos de Vorônski, começando com um artigo datado de 1922: naquele artigo, Vorônski descreve a "felicidade" (rádostnost) presente no clima de vitalidade predominante na obra de Ivanov. ${ }^{18}$ Nota-se um eco desse rótulo de "felicidade" na apresentação editorial de "Um amor brasileiro" em 
30 Dniêi: "A força do talentoso Vsiévolod Ivanov consiste na alegria [rádost] gigantesca com a qual ele percebe a vida, na relação estreita com a nova Rússia, no conhecimento dos tesouros do novo estilo de vida [nôvogo bíta]...". ${ }^{19}$ Maguire sugere que essa reação inicial à poética de Ivanov revela um engano fundamental: o que Vorônski e outros viam como a vitalidade do mundo de Ivanov se transforma, sob um prisma irônico, numa "visão do mundo cínica, niilista, e desesperada" ${ }^{20} \mathrm{De}$ fato, é difícil notar indícios inegáveis de felicidade ou vitalidade em "Um amor brasileiro", no qual Vániuchka decide retornar à União Soviética, não por causa de qualquer convicção absoluta dos ideais comunistas, mas porque ele quer evitar os mesmos erros cometidos por seu pai. Seu "amor brasileiro" perdura depois do retorno à pátria, e Vániuchka continua a sonhar com a possibilidade de rever o Brasil: "...Esse Volga, na cor do rio, se parece com o Amazonas, e em Sarátov... estação ferroviária... trem para Moscou... direto... e além..." ${ }^{21}$ Ivanov deixa a cargo do leitor decidir se essa conclusão promete um futuro feliz para Vániuchka ou não, seja na eterna expectativa do reencontro com Máchenka em Moscou, seja na emigração permanente para o Brasil. Porém, o que fica claro é que as lealdades dele são, em última análise, incompatíveis: por um lado, o país natal, e, por outro, seu amor por uma mulher que, ainda que seja russa de nascença, não se sente atrelada àquele país.

"Um amor brasileiro" é um exemplo inusitado de tradução cultural, um prelúdio adiantado aos contatos que seriam estabelecidos entre figurais culturais soviéticas e brasileiras (e latinoamericanas em geral) durante o período da Frente Popular contra o fascismo e da Guerra Civil Espanhola na década de 1930, num processo que culminará, no período pós-guerra, na explosão de interesse soviético na América Latina durante o Degelo e a Estagnação. ${ }^{22}$ Por um lado, o Brasil do conto parece

19 V. IVANOV, 1926, 20.

20 MAGUIRE, 1987, 133.

21 IVANOV, 1926, 31.

22 Sobre a Frente Popular, v. CLARK, 2011, 169-209. Sobre o período pós-guerra, v. RUPPRECHT, 2015, passim, e DJAGALOV, 2020, 111-136 (sobre intercâmbios entre a União Soviética e o Terceiro Mundo em geral no campo da literatura) e 173-209 (sobre intercâm- 
ser uma compilação de estereótipos sobre mundos exóticos, um país distante povoado por versões orientalizadas de tipos culturais já bem conhecidos do leitor russo. Por outro lado, a escolha do Brasil para a localização da trama indica um interesse concreto nos paralelos existentes entre os dois países, principalmente pela perspectiva de Ivanov, na natureza caracterizada por rios majestosos e florestas. O resultado é um texto cuja importância reside tanto na sua realização final quanto na sua promessa e antecipação dos atos de tradução que caracterizariam os intercâmbios culturais entre a América Latina e a União Soviética nas décadas seguintes.

\section{Referências Bibliográficas}

ANÔNIMO. "K sotzializmu. Sriedniaia Aziia." 30 dniêi, v. 6, n. 1, Moscou, jan. 1930, pp. 30-31.

ASAD, Talal. "The Concept of Cultural Translation in British Social Anthropology". In: BAKER, Mona (Ed.). Critical Readings in Translation Studies. Londres: Routledge, 2010. pp. 7-27.

BROUGHER, V. G. "Vsevolod Viacheslavovich Ivanov (12 February 1895-15 August 1963)". In: RYDEL, Christine (Ed.). Russian Prose Writers Between the World Wars. Detroit: Gale, 2003. p. 161-173.

CASANOVA, Pascale. "Consecration and Accumulation of Literary Capital: Translation as Unequal Exchange". In: BAKER, Mona (Ed.). Critical Readings in Translation Studies. Londres: Routledge, 2010. pp. 285-303.

CLARK, Katerina. Moscow, the Fourth Rome: Stalinism, Cosmopolitanism, and the Evolution of Soviet Culture, 1931-1941. Cambridge, Massachusetts: Harvard University Press, 2011.

DE OLIVEIRA, Cassio. "Why is There a Bull on the Magazine Cover?" The Readers of the Soviet Magazine 30 Days". Slavic and East European Blog, 19 ago. 2018. Disponível em: https:// blog.seej.org/index.php/2018/09/19/why-is-there-a-bull-on-the-

bios na área de documentários). 
-magazine-cover-the-readers-of-the-soviet-magazine-30-days/.

DJAGALOV, Rossen. From Internationalism to Postcolonialism: Literature and Cinema between the Second and the Third Worlds. Montreal e Kingston: McGill-Queen's University Press, 2020.

GANF, Iu. Retrato dos portugueses para o conto "Um amor brasileiro". 30 dniêi, v. 2, n. 2, Moscou, fev. 1926, p. 21.

GANF, Iu. Retrato de Máchenka para o conto "Um amor brasileiro". 30 dniêi, v. 2, n. 2, Moscou, fev. 1926, p. 29.

HULME, Peter; YOUNGS, Tim. "Introduction". In: HULME, Peter; YOUNGS, Tim (Eds.). The Cambridge Companion to Travel Writing. Cambridge: Cambridge University Press, 2002. pp. 1-14.

IVANOV, Vsiévolod. "Brazílskaia liubov". 30 dniêi, v. 2, n. 2, Moscou, fev. 1926, pp. 20-31.

IVANOV, Vsevolod. Fertility and Other Stories. Tradução de Valentina G. Brougher e Frank J. Miller. Evanston: Northwestern University Press, 1998.

KAPPELER, Andreas. The Russian Empire: A Multiethnic History. Tradução de Alfred Clayton. Abingdon, Oxon: Routledge, 2013.

MAGUIRE, Robert A. Red Virgin Soil: Soviet literature in the 1920's. Ithaca: Cornell University Press, 1987.

MARTIN, Terry. The Affirmative Action Empire: Nations and Nationalism in the Soviet Union, 1923-1939. Ithaca: Cornell University Press, 2001.

REGUÍNIN, V. A. "Vistupliênie na pérvoi moskóvskoi konfieriéntsii tchitátelei jurnala 30 Dniêi. Stenogramma. Imiêiutsia vistupliêniia: Koltzova M.E., Gusa M.S. i dr. Machinopis". [s.d.]. Rossíiskii gossudárstviênnii arkhiv litieratúri i iskússtva (RGALI), fond 1433, opis 3, edinitsa khraniênia 90.

RUPPRECHT, Tobias. Soviet Internationalism after Stalin: Interaction and Exchange between the USSR and Latin America during the Cold War. Cambridge: Cambridge University Press, 2015.

SITKOV, I. "Soviétskii 'magazin' - '30 dniêi'". Kniga i revoliút- 
ziia, n. 8, Moscou, 20 abr. 1929, p. 38-39.

VENUTI, Lawrence. The Translator's Invisibility: A History of Translation, 3a edição. Nova York: Routledge, 2018.

Recebido em: 15/09/2020

Aceito em: 18/11/2020

Publicado em dezembro de 2020 